This is the final manuscript author version. (C2018. This manuscript version is made available under the CC-BY-NC-ND 4.0 license http: //creativecommons .org/licenses/by-nc-nd/4.0/ doi:10.1016/j.energy.2018.08.093

\title{
Environmental impact indicators for the electricity mix and network development planning towards 2050 - a POLES and EUTGRID model
}

\author{
Jean-Nicolas Louis $^{\mathrm{a}, *}$, Stéphane Allard ${ }^{\mathrm{b}, \mathrm{c}, \mathrm{d}}$, Vincent Debusschere ${ }^{\mathrm{b}}$, Silvana Mima ${ }^{\mathrm{c}}$, Tuan Tran-Quoc ${ }^{\mathrm{d}}$, Nouredine Hadjsaid ${ }^{\mathrm{b}}$ \\ ${ }^{a}$ University of Oulu, Faculty of Technology, Energy and Environmental Engineering, P.O.Box 4300, FI-90014 Oulu, Finland \\ ${ }^{b}$ Univ. Grenoble Alpes, CNRS, Grenoble INP ${ }^{1}$, G2Elab, 38000 Grenoble, France \\ ${ }^{c}$ Univ. Grenoble Alpes, CNRS, Grenoble INP ${ }^{1}$, GAEL/EDDEN, INRA, 38000 Grenoble, France \\ ${ }^{d}$ CEA-INES, 50 avenue du Lac Léman, 73375 Le Bourget-du-Lac, France
}

\begin{abstract}
Most prospective studies of the European power system rely on least-cost evaluations. This study assessed the influence of environmental impact indicators on prioritisation of 'dispatchable' technologies in the European energy mix up to 2050, compared with a purely cost-optimal system based on carbon tax incentives, without suppressing economic growth considerations. A model that combined the Prospective Outlook for Long-term Energy Systems model (POLES) and the European and Transmission Grid Investment and Dispatch model (EUTGRID)was used in the analysis. Combined current and prospective life cycle assessment (LCA) methodologies were added to the EUTGRID model to include environmental considerations in the decision-making process. Shifting from an economic to an environmental merit order in prioritisation increased the share of renewables by $2.65 \%$ (with variations between countries) and decreased overall emissions by $9.00 \%$. This involved a change in grid infrastructure. Investments were found to be more important when optimisation was based on an environmental criterion on new high-voltage AC power lines, which resulted in a $1.50 \%$ increase in the overall cost of the power system. Finally, considering an environmental, instead of an economic, merit order allowed decarbonisation to be achieved slightly faster, resulting in lower cumulative greenhouse gas emissions to the atmosphere.
\end{abstract}

Keywords:

Environmental emissions, Electricity modelling, POLES, EUTGRID, Environmental merit order, economic merit order

\section{Long term energy systems planning}

\subsection{Context}

The Kyoto protocol requires countries to meet at conferences of parties (COP) to discuss and set individual objectives ${ }_{21}$ for each country wishing to contribute to decreasing anthropogenic impacts and better protect the global environment. In ${ }^{22}$ 2015, the COP was held in Paris and resulted in what is known ${ }^{23}$ as the Paris agreement [44], under which every ratifying coun- ${ }^{24}$ try agrees to preventing the global temperature rising above the ${ }^{25}$ critical level of $2^{\circ} \mathrm{C}$ by 2100 compared with the 'pre-industrial' era [22].

The energy sector must also change, in order to handle pop- ${ }^{28}$ ulation growth, and the related increase in energy demand, while ${ }^{29}$ still maintaining the same level of services and reliability. Mean- ${ }^{30}$ while, emissions from energy production must decrease drasti- ${ }^{31}$ cally if agreements reached in COPs are to be kept. For in- ${ }^{32}$ stance, in 2009, the European Council encouraged its member ${ }^{33}$

\footnotetext{
${ }^{*}$ Corresponding author. Tel: +358294487607.

Email addresses: jean-nicolas.louis@oulu.fi (Jean-Nicolas Louis), stephane.allard@grenoble-inp.fr (Stéphane Allard), vincent . debuss chere@grenoble-inp.fr (Vincent Debusschere), silvana.mima@univ-grenoble-alpes.fr (Silvana Mima), QuocTuan.Tran@cea.fr (Tuan Tran-Quoc), nouredine.hadj said@grenoble-inp.fr (Nouredine Hadjsaid)

${ }^{1}$ Institute of Engineering Univ. Grenoble Alpes
}

1.

22

101
\section{acdi} \section{.}

The European Commission mainly uses the partial equilibrium Price-Induced Market Equilibrium System (PRIMES) energy model to evaluate the impact of climate policy on the European energy system [13]. The PRIMES model projects scenarios considering a five-year time step for the energy sector in all European countries. To better illustrate each sector, PRIMES is linked to other models describing e.g. non- $\mathrm{CO}_{2}$ emissions, 35 exogenous factors (e.g. gross domestic product, fossil energy ${ }_{36}$ prices), transportation or biomass usage. It covers a wide range of the technologies used for energy production, including various investment schemes for the electric grid and Renewable Energy Sources (RES) integration. The power sector has a resolution at the level of the country and interconnections are represented to show the dynamics of the power system. The latest

August 29, 2018 
This is the final manuscript author version. (C2018. This manuscript version is made available under the CC-BY-NC-ND 4.0 license http: //creativecommons.org/licenses/by-nc-nd/4.0/ doi:10.1016/j.energy.2018.08.093

\section{Glossary}

COP Conferences of parties

EDGAR

\section{ETS}

ETSAP

EUCAD

EUTGRID

HVAC

HVDC

LCA

LCI

NEEDS

POLES

PRIMES

RES

TIMES

VRES
Emission Database for Global Atmospheric Research

\section{Emission trading scheme}

Energy Technology Systems Analysis Program

European Unit Commitment And Dispatch model

European - Transmission Grid Investment and Dispatch

$$
\text { high voltage } \mathrm{AC}
$$

high voltage DC

Life Cycle Assessment

$$
\text { Life cycle inventory }
$$

New Energy Externalities Development for Sustainability

Prospective Outlook for Long-term Energy Systems

Price-Induced Market Equilibrium System model

\section{Renewable Energy Sources}

The Integrated MARKAL-EFOM System

Variable renewable energy sources development concerning the power system sector includes an equivalent of the transmission network considering electricity curtailment, interconnections and line congestion. This add-on is called PLEXOS, an additional module to PRIMES [5]. It results in a meshed network of a balanced system using a single point per country focusing on the year 2030.

Another widely used model for representation of the energy sector is the Integrated MARKAL-EFOM System (TIMES) model [32] developed by the Energy Technology Systems Analysis Program (ETSAP), which has branches in over 20 countries. The TIMES model is a least-cost equilibrium model for technology and economic energy supply and demand over a defined time horizon and a yearly minimum granularity. The model can be extended to integrate regional endogenous factors, and thus multiple TIMES models co-exist for specific usages.

\subsection{Environmental impact indicators}

All these models aim at better addressing climate change challenges through prospective scenarios, thereby contributing to limiting the increase in mean global temperature. Environmental emissions are estimated in technical and economic analysis, including the six greenhouse gases emitted directly from combustion processes as listed in the Kyoto protocol [43]. For this reason, Pang et al. [35] emphasise the need for other indicators that consider various environmental impacts. In particular, to implement the European climate legislation, new modelling tools for assessing environmental impact that can use Life Cycle Assessment (LCA) for integrated evaluations are needed [36].

The use of LCA indicators in integrated assessment models in order to take a snapshot of environmental impacts of future possible energy mixes is increasing [2]. A recent study examined the influence of using LCA results, including indirect emissions, in decision making on future technology deployment [34]. It concluded that integrating indirect emissions resulted in lower penetration of variable renewable energy source (VRES) installed capacity. The use of LCA indicators in optimising the electricity sector has been studied in the case of Norway by García-Gusano et al. [19] and further tested in the Spanish context [20]. These optimisations reveal the impact of using LCA indicators during the electricity production phase. Including the impacts in the entire life cycle could increase total emissions by $50 \%$ [37]. Challenges arise in defining a unified methodology for including LCA results in the decision-making process [40]. Moreover, the impact on infrastructure of integrating more VRES and the infrastructure investments needed to support such developments have not been well studied.

The current incentive to increase the share of renewable energy sources (RES) is the Emissions Trading Scheme (ETS), which sets carbon prices and drives the technology development market. In this system, biomass-based power production receives specific treatment, as it is excluded from the ETS under the biomass zero-treatment scheme [17]. As this may compromise evaluation of emissions and decision making on choice of technologies, there has been a call for emissions from biomass to be integrated in the next ETS framework [45]. 
This is the final manuscript author version. (C2018. This manuscript version is made available under the CC-BY-NC-ND 4.0 license http: //creativecommons .org/licenses/by-nc-nd/4.0/ doi:10.1016/j.energy.2018.08.093

\subsection{Objectives of the present study}

The main objective of this study was to assess the influence ${ }^{151}$ of environmental impact indicators on prioritisation of 'dispatch ${ }^{152}$ able' technologies in the energy mix, and thus the environmen- ${ }^{153}$ tal impact on climate change, and the infrastructure costs in- ${ }^{154}$ volved in that change of paradigm. The environmental impact ${ }^{155}$ of current technologies changes over time and therefore needs ${ }^{156}$ to be compared against the environmental impact of prospective technologies. This secondary objective was necessary to ${ }^{157}$ achieve the main one and represents an additional methodolog-158 ical contribution of the study. In the analysis, economic growth ${ }_{159}$ remained the basis of prospective computations run by POLES, 160 while environmental criteria were taken into account in the op-161 timisation process.

Section 2 of this paper describes the models used to im-163 plement direct and indirect emissions into the decision-making ${ }_{164}$ process on 'dispatchable' technologies and the adapted regional ${ }_{165}$ environmental impact database for the production technologies 166 present in the energy models. The objective function to min-167 imise emissions from 'dispatchable' technologies is presented ${ }_{168}$ in Section 3. The results are presented and discussed in Section ${ }_{169}$ 4 , in relation to other ongoing research. Section 5 presents the 170 main conclusions.

\section{Modelling energy systems and environmental impacts}

This study was conducted using two interconnected mod-175 els: the Prospective Outlook for Long-term Energy Systems ${ }^{176}$ (POLES) $[8,27]$ and the European Transmission Grid Invest-177 ment and Dispatch (EUTGRID) [1], an extension of the Euro- ${ }^{178}$ pean Unit Commitment And Dispatch (EUCAD) model devel-179 oped by Després et al. [10].

\subsection{The POLES model}

POLES is a bottom-up model of the world-wide energy sec- ${ }^{183}$ tor. It was developed in the 1990s and was fully deployed in ${ }^{184}$ 1997. POLES has since been upgraded several times and is cur- ${ }^{185}$ rently in its $6^{\text {th }}$ version. It is being refined concurrently by the ${ }^{186}$ Joint Research Center (JRC) [26], the Sustainable Development ${ }^{187}$ and Energy Economics laboratory at the University of Greno- ${ }^{188}$ ble (GAEL-EDDEN) [14], and the energy consulting company ENERDATA [15]. The POLES model allows the energy sector ${ }^{18}$ to be simulated up to the year 2100. Simulations in POLES are ${ }^{190}$ based on partial equilibrium, which requires exogenous data. ${ }^{191}$ The input data to the model, such as population and gross do- ${ }^{192}$ mestic product (GDP), are set using the work of the JRC to ${ }^{193}$ define reference scenarios [26, 28, 25].

Among the different energy sectors covered, the electricity ${ }^{195}$ production is modelled by including 41 current and prospec-196 tive technologies (refer to Table A.3 in appendix). In order to ${ }^{197}$ characterise electricity production as an output, POLES consid- ${ }^{198}$ ers exogenous parameters such as GDP alongside population changes and carbon constraints, which are included by setting a carbon price within the system. Furthermore, market data are included using resources constraints and the interdependencies between fuel prices and fuel demand. Other outputs are also available, such as greenhouse gas emissions, system prices and energy consumption for each year and country within the model's scope. However, POLES lacks a representation of developments in the electricity grid and its components, such as storage. As storage technologies will be crucial for large-scale deployment of VRES, an optimisation tool that considers all these aspects is needed [9].

\subsection{The EUCAD/EUTGRID}

In order to integrate new aspects of the European electricity grid, an external module that optimises the EUCAD model has been developed [11,9]. Recently, transmission line investments were incorporated within a finer geographical resolution of the European electricity grid, in an updated module (EUTGRID) [1]. Transmission planning is critical for best incorporating production of VRES that considers the optimal balance between economic and technical constraints [47]. The model considers the development of both high-voltage alternating current (HVAC) and high-voltage direct current (HVDC). The EUCAD/EUTGRID module is based on an optimisation problem, interfaced with POLES, developed in GAMS and uses the CPLEX solver. This module considers the 41 technologies present in POLES for energy production (Table A.3). It implements storage elements, characterised by their temporal variations, by simulating hourly electricity production, demand, international exchange and load curtailment. EUTGRID is limited to 24 countries within the European Union (EU24) that are present in POLES ${ }^{2}$. Each country is divided into a variable number of clusters representing the transmission network connections within the country. In total, the model considers 87 clusters. For each simulated year, two typical load days (one for summer and one for winter) and 12 representative VRES production days are modelled: 6 days for the summer period and 6 days for the winter period. Each represents 12 distinct VRES constraints that could statistically occur on the European electricity grid. Ultimately, the EUTGRID module aims at minimising operation costs at the European level. To achieve a balance of electricity demand and production at the European level, it maximises the use of VRES in the network and adjusts the production of other technologies to meet its initial objective.

\subsection{Environmental impact of production technologies}

To minimise the emissions of the entire power system, the environmental impact of each technology must be known. One of the limitations in existing studies is that the environmental impact of technologies for power production is limited to evaluation of: i) only equivalent carbon dioxide emissions $\left(\mathrm{CO}_{2 \mathrm{eq}}\right)$, meaning that all other environmental impacts are intentionally disregarded; ii) combustion technologies, for their direct contribution to global warming; and iii) the six Greenhouse Gases (GHG) listed in the Kyoto protocol. Furthermore, technologies

${ }^{2}$ EU24: Austria, Belgium, Bulgaria, Switzerland, Czech Republic, Germany, Denmark, Spain, Finland, France, Great-Britain, Greece, Hungary, Ireland, Italy, Luxembourg, The Netherlands, Norway, Poland, Portugal, Romania, Sweden, Slovakia, Slovenia mix and network development planning towards 2050 - A POLES and EUTGRID model, Energy, 163, 2018, p.618-628, doi:10.1016/j.energy.2018.08.093 
This is the final manuscript author version. (C2018. This manuscript version is made available under the CC-BY-NC-ND 4.0 license http: //creativecommons .org/licenses/by-nc-nd/4 .0/ doi:10.1016/j.energy.2018.08.093

based on similar fuels are considered identical, as primary en-250 ergy consumption is used to consider $\mathrm{CO}_{2 \mathrm{eq}}$ emissions. This re-251 sults in a misleading representation of the overall environmental 252 impact in which there are geographical specificities, including 253 environmental culture and long-term policy planning [12]. For 254 example, a coal power plant will have different emissions in 255 different countries. The decision-making process must reflect 256 this particularity.

To this end, use of LCA methodology, based on the EcoIn-258 vent 3.01 database, can be advantageous [46]. The EcoInvent 259 database provides the life cycle inventory (LCI) for multiple en-260 ergy production technologies and multiple regions. Each LCI is 261 further characterised using the ReCiPe2008 methodology [21].262 In order to compute the environmental impact for each technol-263 ogy, these technologies are divided into current technologies264 and prospective technologies (Table A.3 in appendix). Further-265 more, biomass-based technologies are taken into account until266 the electricity production phase without reallocating the $\mathrm{CO}_{2267}$ produced during the production phase. This avoids allocation 268 issues, as well as accounting only for the $\mathrm{CO}_{2}$ actually emitted.269 The methods for building the database are presented in Figure $1_{270}$ while characterised data are available as supplemental informa-271 tion (SI) [31].

\subsubsection{Current technologies}

The first step towards including the environmental impacts 275 of power production technologies is to obtain a preliminary276 overview of these impacts. Of the 41 technologies used in the277 POLES model, LCA for 28 of these are available in the EcoIn-278 vent database. These LCA do not represent the full life cyclez79 but rather cradle-to-product, including the waste management280 stream but disregarding the end-of-life phase of infrastructure. 281 Therefore, we decided to consider the emissions within these life cycle boundaries.

The output is the generation of a three-dimensional ${ }^{3}$ matrix $F_{i, j, k, l-T o d a y}$ where $k$ is the characterised emission factor for $_{282}$ each technology $j$ (expressed per GWh), for different clusters ${ }_{283}$ $i$, and all European countries $l$. The characterised environmen- ${ }_{284}$ tal impacts are not available for all countries (e.g. no marine 285 technologies for countries without coastlines, technology not ${ }_{286}$ currently present in the country etc.). Therefore, each coun- ${ }_{287}$ try lacking a technology was consolidated using data available ${ }_{288}$ in other countries. Impossible solutions such as tidal power ${ }_{289}$ production in central Europe were resolved in a higher level $\mathrm{in}_{290}$ POLES that does not allow such combinations. Thus, although ${ }_{291}$ environmental impacts are associated with all countries, this did not affect the decision making of the optimisation tool. Note that all data are available in SI [31].

\subsubsection{Future and prospective technologies}

Amongst the pool of technologies included in the EUTGRID ${ }^{29}$ model, some are considered prospective. Prospective technolo- ${ }^{295}$ gies are not only future non-existent technologies, but also tech- ${ }^{296}$

${ }^{3} 41$-by-24-by-18 - 41 technologies, 24 countries and 18 characterised indi-299 cators as in $\mathrm{ReCiPe}$. nologies that are in the pilot phase. Therefore, the environmental impact of these technologies is not known and must be estimated. For this, we used data assessing the full costs and benefits of the future energy system taken from the New Energy Externalities Development for Sustainability (NEEDS) database [38] database. The NEEDS model comprises five scenarios: Pessimistic Business as Usual $(P-B A U)$, Pessimistic $440 \mathrm{ppm}$ (P-440ppm), Realistic-Optimistic 440 ppm (RO-440ppm), very optimistic $440 \mathrm{ppm}$ (VO-440ppm), very optimistic based on a renewable energy electricity (VO-Renew). Each of the five scenarios is detailed for the period until 2025 and 2050. The NEEDS database is based on the EcoInvent v1.3 database, which is an obsolete version considering the different aggregation of products. However, we left technologies that are still considered prospective as described in the NEEDS database, while we removed incorrect products that are misplaced as outputs in the technologies (e.g. tidal and wave energy, concentrated solar power plants etc.).

To overcome the changes between the different versions of the EcoInvent database, we downgraded the EcoInvent database for the current technologies to similar products that appear in the NEEDS database $\left(F_{i, j, k, l-T o d a y} \rightarrow F_{N E E D S-T o d a y}\right)$. Therefore, products appearing in the latest version of the EcoInvent database were not integrated into the system. This did not affect the output for any of the indicators characterised except water depletion, human toxicity and land occupation. The main reason why this was done was to avoid discrepancies between the database of prospective technologies and that of current technologies, while computing the prospective emissions of power production technologies for every country. Thus for each technology present in the NEEDS database, the ratio between the current scenario and prospective scenarios was calculated as:

$$
f_{i, j, k, l-\text { ratio }}=\left(\frac{F_{\mathrm{NEEDS}-\text { scenario }}}{F_{\mathrm{NEEDS}-\text { Today }}}\right)-1
$$

where $f_{i, j, k, l-\text { ratio }}$ is the ratio of a specific product's emissions between the current scenario and a given prospective scenario [\%], $F_{\mathrm{NEEDS}-\text { Today }}$ is the emissions for a specific product in the LCI of a technology for the current scenario, and $F_{\text {NEEDS-scenario }}$ is the emissions for the same specific product in the LCI of a technology for the prospective scenario.

Once the ratio for each product is calculated, it is possible to obtain, for each technology, country and prospective scenario, a database that reproduces the emissions behaviour of the existing technology in $F_{i, j, k, l-\text { Today }}$.

$$
F_{i, j, k, l-\text { Scenario }}=F_{i, j, k, l-\text { Today }} \times f_{i, j, k, l-\text { ratio }}
$$

where $F_{i, j, k, l-S c e n a r i o}$ is the LCI of all technologies for the prospective scenario. It is further characterised using the $\mathrm{ReCiPe} 2008$ method to evaluate the emissions for specific indicators.

Finally, when a technology was not available in either the EcoInvent database or the NEEDS database, information from the literature was considered. This was the case for solar concentrated technology, for which a study carried out in Spain was used [6]. In that study, the authors claimed [39] that 'the indicators published in that paper are the most pertinent to the 
This is the final manuscript author version. (2018. This manuscript version is made available under the CC-BY-NC-ND 4.0 license http://creativecommons.org/licenses/by-nc-nd/4.0/ doi:10.1016/j.energy.2018.08.093

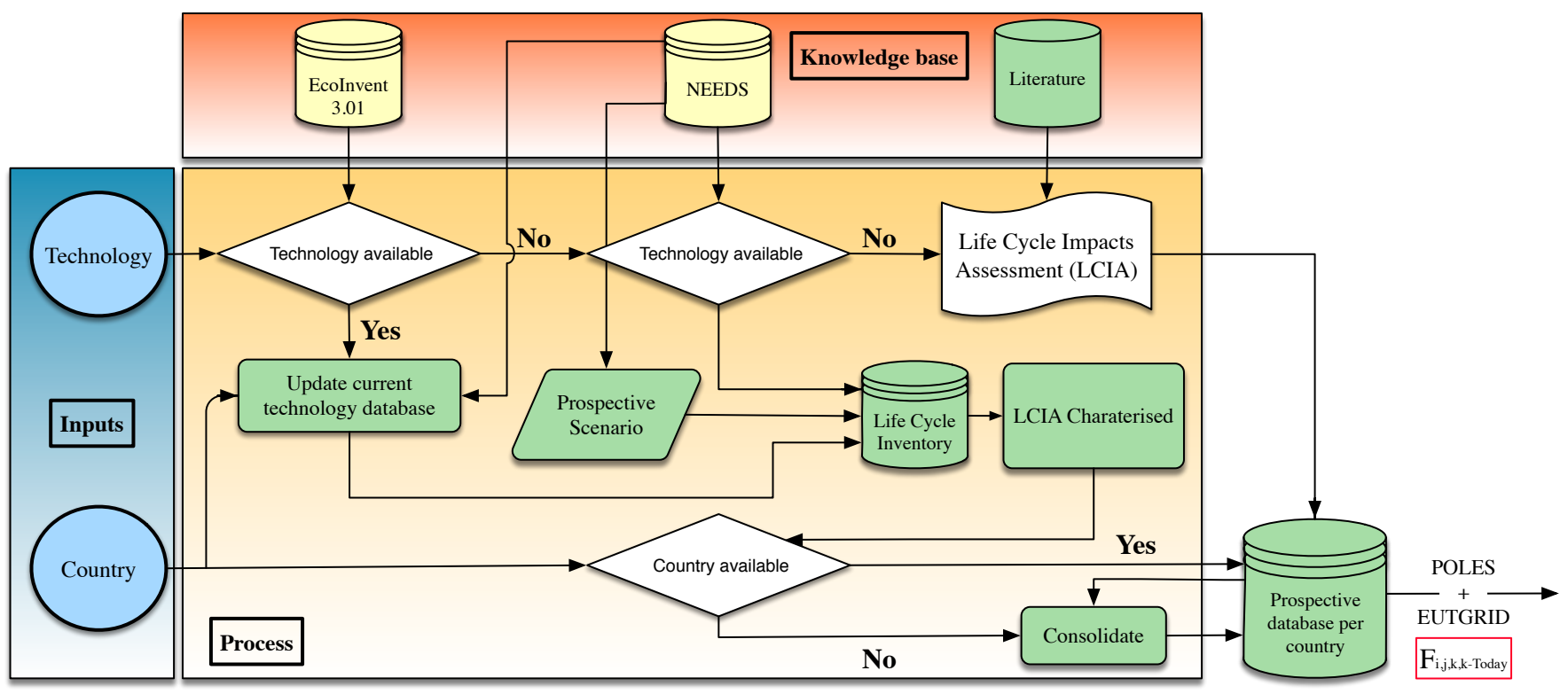

Figure 1: Prospective environmental impact database used with the EUTGRID model.

technology. We believe that results from all other indicator $\$_{3 з 0}$ are not relevant to this investigation, due to high uncertainty.',331 and therefore disregarded them in their environmental impact assessment study. All data are available as SI [31].

\section{Environmental optimisation method}

The main objective of the environmental optimisation methơ is to minimise the environmental emissions $k$. The impact indi- ${ }^{338}$ cators given in the ReCiPe 2008 method for environmental im- ${ }^{339}$ pact assessment are used (see Table A.2 in appendix). These $18^{340}$ indicators reflect the impact of a process or technology on e.g. ${ }^{341}$ climate change, water depletion, ionising radiation or ozone ${ }^{342}$ depletion. In order to achieve the environmental optimisation ${ }^{343}$ goal, yearly emissions for a selected indicator $k$ are calculated ${ }^{344}$ for the energy mix optimised in the upstream process of the ${ }^{345}$ EUTGRID model. The objective function to minimise is: $\quad{ }^{346}$

$$
\min \left(E_{\text {m,Europe- } k}\right)=\sum_{i, j, k, l, t}\left(F_{i, j, k, l} \times P_{i, j, t}\right)
$$

where $E_{m, \text { Europe- } k}$ is the total yearly emissions for a given indi- ${ }^{350}$ cator $k$. In the overall emissions $F, k$ is the characterised emissions factor for each technology $j\left[/ \mathrm{GWh}\right.$, for different clusters ${ }_{351}$ $i$, and all European countries $l . P$ is the power production for each cluster $i[\mathrm{GW}]$, for each technology $j$ and each yearly sce-352 nario $t[\mathrm{~h}]$. The characterised emissions of $F_{i, j, k, l-S c e n a r i o}$ and $^{353}$ $P_{i, j, t}$ are the energy produced $F_{i, j, k, l}[\mathrm{GWh} / \mathrm{h}]$.

The minimisation is used for two purposes: to recalculate ${ }^{355}$ the electricity produced by the 'dispatchable' production units ${ }^{356}$ and to set the investments to be made on the transmission net- ${ }^{357}$ work. The EUTGRID model computes different energy mixes ${ }^{358}$ for 12 representative days considering physical and economic ${ }^{359}$ constraints. Constraints are described in the EUTGRID de-360 scription model $[10,1]$ and comprise the minimum OFF and ${ }^{361}$
ON times and the ramping time per technology, the storage, demand response, electric vehicle constraints and the 'dispatchable' loads. Moreover, the investments on transmission line reinforcements are recalculated every three years using prospective environmental emissions. In order to achieve this, the EUTGRID model uses a three-year rolling window: at the beginning of the period, investments are based on the expected electricity mix on a 10-year time horizon from the current year provided by POLES to alleviate future bottlenecks; and at the end of the period, investments are determined using the actual electricity mix to solve possible existing congestions. We also used this mechanism to plan investments (line reinforcment) based on the expected emissions for the given electricity mix.

We divided the model into three periods, spanning 20002050. The period 2000-2012 was used for calibrating the model and was based on historical information from POLES. The second period, 2013-2025, included the environmental impact objectives only using the current database. In 2025, the environmental impacts were updated with the prospective database using the five scenarios mentioned in section 2.3.2. These environmental impacts were used until 2050.

\section{Results and discussion}

The model was run over the period 2000-2050 with an investment period of three years and a yearly energy mix optimisation that satisfied 12 hourly-scenarios ( 6 for the summer period, 6 for the winter period). The results are analysed below considering the energy mix per country, environmental emissions and the economic aspect of reinforcing or creating new lines (both HVAC and HVDC technologies).

The combined model makes it possible to assess how each European country needs to invest in its transmission network in order to maximise the use of RES using an environmental merit 
This is the final manuscript author version. (C2018. This manuscript version is made available under the CC-BY-NC-ND 4.0 license http: //creativecommons .org/licenses/by-nc-nd/4 .0/ doi:10.1016/j.energy.2018.08.093

order under technical constraints, instead of the more conven-413 tional economic merit order of technologies. In other words, the ${ }_{414}$ model uses the $2^{\circ} \mathrm{C}$ climate policy of each country and adjusts 415 the electricity mix accordingly.

\subsection{The share of RES}

We analysed the share of RES in the electricity mix of each ${ }^{419}$ country from the perspective of their production, thus excluding ${ }^{420}$ the import and export share of the electricity mix.

$$
P_{R E S}=\frac{P_{\text {Bio }}+P_{\text {Sol }}+P_{\text {Wind }}+P_{\text {Hydro }}+P_{\text {Earth }}-P_{\text {Curt }}}{P_{\text {Tot }}}
$$

where $P_{\text {res }}$ is the ratio of RES production within a country ${ }^{42}$ [\%], $P_{B i o}$ is the power production for Biomass, $P_{S o l}$ the solar ${ }^{427}$ power, $P_{\text {Wind }}$ the onshore and offshore wind power, $P_{H y d r o}$ the ${ }^{428}$ hydro-power, $P_{\text {Earth }}$ the geothermal energy, and $P_{C u r t}$ in case ${ }^{429}$ curtailment is necessary. The total power produced within a ${ }^{430}$ country is $P_{T o t}$.

The share of RES in the electricity mix on the consumption ${ }^{432}$ side, including the electricity trading of RES, is reported in SI. ${ }^{433}$ The share of RES in the national production mix is presented in ${ }^{434}$ Figure 2 for the years 2000 and 2050.

The general trend was naturally an increase in RES in the electricity mix of all European countries throughout the period 2000-2050. Countries that devoted the most effort to RES de- ${ }^{43}$ ployment were those with the lowest RES share in 2000, e.g. ${ }^{438}$ Hungary, Poland, Czech Republic, Belgium. In contrast, coun- ${ }^{439}$ tries with a high share of RES in 2000 showed the weakest in- ${ }^{-40}$ crease in terms of RES share over time, e.g. Norway, Swe- ${ }^{44}$ den, Austria, Finland. By 2050, the 24 countries had integrated ${ }^{442}$ $51.4 \%$ of RES into the European electricity network. Countries ${ }^{433}$ in eastern Europe continued to have the lowest share of RES ${ }^{44}$ in their electricity mix. The countries that progressed most be- ${ }^{445}$ tween 2000 and 2050 were Slovenia $(3.40 \% \rightarrow 54.7 \%)$, Greece ${ }^{446}$ $(10.2 \% \rightarrow 70.2 \%)$ and Germany $(4.70 \% \rightarrow 59.3 \%)$. Countries ${ }^{447}$ that showed the lowest increase were Slovakia $(13.1 \% \rightarrow 23.6 \%)^{48}$ the Netherlands $(11.9 \% \rightarrow 34.0 \%)$ and Finland $(43.0 \% \rightarrow 53.0 \%)$ In the case of Finland, the main reason was an increase in the nuclear share in the energy mix, which counter-balanced the ${ }^{45}$ effect of VRES penetration, while biomass-based technology ${ }^{452}$ was already prominent [24]. Moreover, the prospect for new hydropower plants is limited due to the geographical specifici- ${ }^{454}$ ties of Finland. In the case of Slovakia, the low increase was a political outcome, as the Slovakian government seems to priori- ${ }^{456}$ tise biomass-based electricity production and nuclear produc- ${ }^{45}$ tion for decarbonising electricity production, while VRES are ${ }^{458}$ avoided because of their higher costs of installation, production ${ }^{459}$ and management $[23,29]$.

Optimising the electricity system based on environmental ${ }^{46}$ criteria increased the use of RES by $2.65 \%(\sigma=5.48)$ at the $e^{462}$ EU24 level by 2050 compared with a system based on eco- ${ }^{463}$ nomic criteria only. The main difference was a decreased use ${ }^{464}$ of coal and gas in the environmental optimisation $\left(-21.7 \%\right.$ and $^{465}$ $-9.00 \%$, respectively). This was partly compensated for by use ${ }^{46}$ of oil power in the electricity mix and increased use of offshore ${ }^{467}$ wind turbines. The share of RES increased most for Austria $(+22.0 \%)$. This was attributable to a change of strategy between the emissions objective and the costs objective. In optimisation of costs for Austria, there was an increase in power production and therefore an increase in export of electricity to trading partners. In optimisation of emissions, the production level decreased overall and Austria became a significant country regarding its share of RES in power production.

Thus, considering the RES share as the ratio of production of electricity from RES to total production by the country benefited most countries by increasing their exchanges and decreasing their national production.

Finally, the RES share decreased in optimisation of emissions for three countries, namely Denmark, Hungary and Norway. This seems contradictory to the goal of this form of optimisation. In the case of Hungary, nuclear production increased significantly and resulted in higher exports, which in turn decreased the RES ratio. In the case of Denmark, imports decreased by $77.0 \%$ and were replaced by increased oil and gas production. Finally, in the case of Norway, the change derived from a shift from excess production and a high export mechanism to lower production from biomass and coal, which decreased the overall RES ratio of Norway $(-3.60 \%)$.

\subsection{Changes in emissions}

The POLES model uses historical data from 2000 to 2012. Optimisation started from the year 2013, considering the environmental impacts of the electricity mix. This explains the sudden drop in climate change emissions $\left(\mathrm{CO}_{2 \mathrm{eq}}\right)$ shown in Figure 3. Note that, even if the optimisation criterion is based on an environmental assessment, economic growth considerations are automatically taken into consideration by POLES and thus are not omitted even when considering environmental criteria. Thus, the optimisation loop contains POLES without interfering directly with its economic prospective computations.

As time passed and climate policy was enforced in every country, the emissions due to electricity generation decreased for both the economic and environmental optimisation methods (Figure 3). By 2050, optimisation using economic criteria decreased emissions by $72.0 \%$ compared with 2000 , while optimisation using environmental criteria decreased emissions by $81.0 \%$ on average for the five environmental scenarios. The gap between the two optimisations decreased in absolute terms and tended to converge eventually (Figure 3 ). This tendency suggests that, in general, economic optimisation would be sufficient to operate the electricity system considering the climate change emissions target. However, climate change emissions under environmental optimisation were always lower, by on average $22.0 \%$, and even $27.0 \%$ in the case of the very optimistic 440 ppm scenario.

To test the robustness of the combined model, three datasets were used: the outcome of PRIMES for future emissions up to 2050; the historical emission values from EuroStat; and the Emissions Database for Global Atmospheric Research (EDGAR) [7], which also records emissions per country and industrial sectors such as the power sector. PRIMES, unlike the other sources, reports the $\mathrm{CO}_{2 \mathrm{eq}}$ emissions for electricity and district

J-N. Louis, S. Allard, V. Debusschere, S. Mima, T. Tran-Quoc, N. Hadjsaid, Environmental impact indicators for the electricity mix and network development planning towards 2050 - A POLES and EUTGRID model, Energy, 163, 2018, p.618-628, doi:10.1016/j.energy.2018.08.093 
This is the final manuscript author version. (C2018. This manuscript version is made available under the CC-BY-NC-ND 4.0 license http: //creativecommons.org/licenses/by-nc-nd/4.0/doi:10.1016/j.energy.2018.08.093

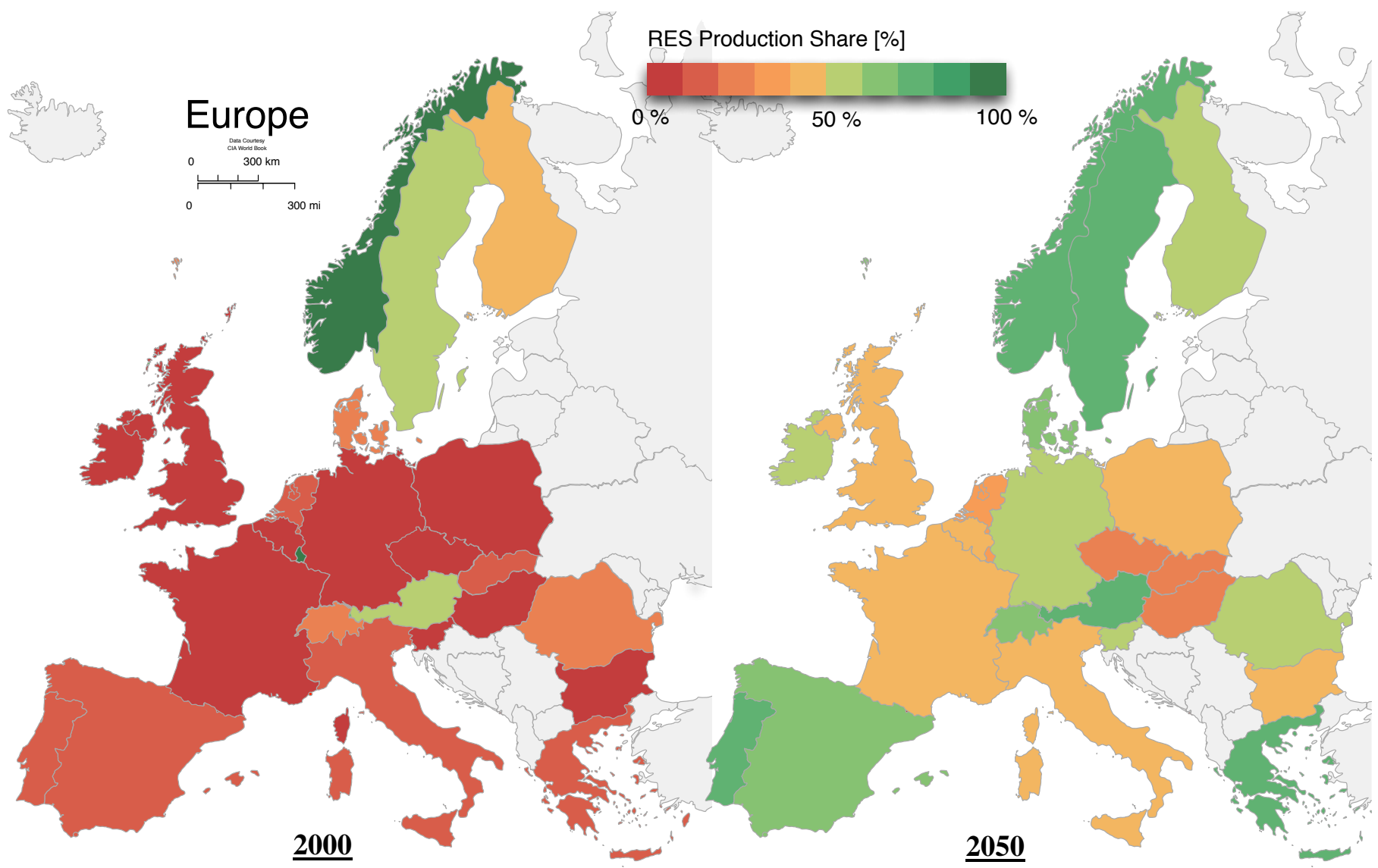

Figure 2: Share of renewable energy sources (RES) production within the domestic electricity production mix for Europe (24 countries) in 2000 and 2050 under the $2^{\circ} \mathrm{C}$ climate policy framework and the VO-440 ppm prospective environmental impact of technologies by minimising the environmental impact of electricity production.

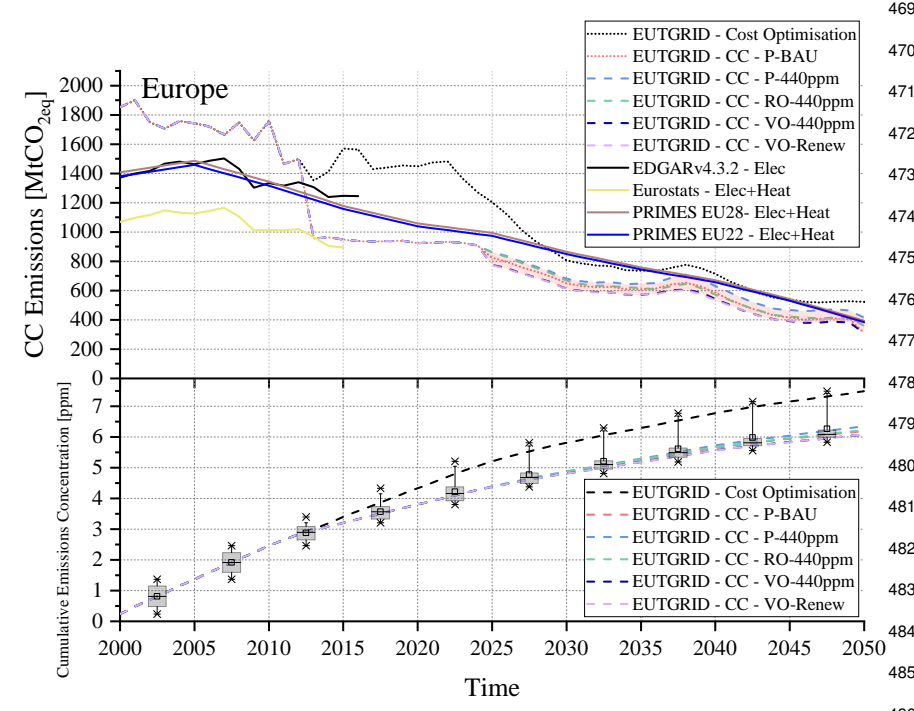

Figure 3: Climate change (CC) impact for the different optimisations from $2000^{487}$ to 2050 under the $2^{\circ} \mathrm{C}$ climate policy framework including both direct and indi-488 rect emissions for all technologies (see section 2.3.2 for abbreviations). Carbon 489 dioxide equivalent $\left(\mathrm{CO}_{2 \mathrm{eq}}\right)$ emissions from Eurostat and the PRIMES model include both heat and electricity and only consider direct $\mathrm{CO}_{2 \mathrm{eq}}$ emissions from ${ }^{490}$ the six GHG listed in the Kyoto protocol, plus nitrogen trifluoride.

J-N. Louis, S. Allard, V. Debusschere, S. Mima, T. Tran-Quoc, N. Hadjsaid, Environmental impact indicators for the electricity mix and network development planning towards 2050 - A POLES and EUTGRID model, Energy, 163, 2018, p.618-628, doi:10.1016/j.energy.2018.08.093 heating combined. In addition, Switzerland and Norway are not included in the PRIMES model and therefore we split the emissions between the reported EU28 and the 24 countries considered in the EUTGRID model, deducting Norway and Switzerland.

An F-test applied to the ANOVA results showed no significant differences $(p>0.05)$ in mean values between the EUTGRID and the EDGAR emissions reports for the period 20002016 The statistical spread of the climate change indicators is presented in Figure 4.

One of the main reasons why the EUTGRID model gives higher emissions levels than the other reference points is that it includes both direct and indirect emissions for all technologies.

For the period from 2000 to 2050, the PRIMES and EUTGRID models with environmental optimisation did not give statistically significant variations in means. However, the differences in means between all environmental objectives and the costs objective were significant $(\mathrm{p}<0.05)$. This could indicate that in a large-scale, long-term perspective, using an LCA future path scenario may not be pertinent in this case (although giving a difference of $19.0 \%$ between the lowest and highest scenario by 2050). When the emissions level is drastically reduced, it does not make much difference whether emissions are characterised using a pessimistic or an optimistic scenario 
This is the final manuscript author version. (C2018. This manuscript version is made available under the CC-BY-NC-ND 4.0 license http: //creativecommons.org/licenses/by-nc-nd/4.0/ doi:10.1016/j.energy.2018.08.093

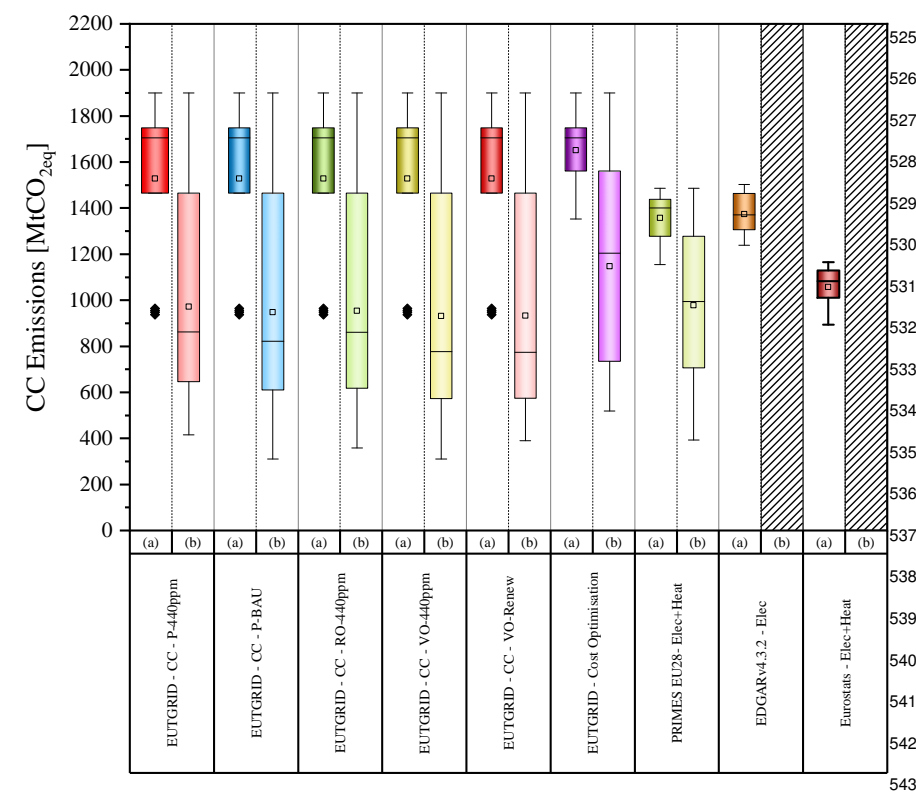

Figure 4: Climate change (CC) impact statistics for the different optimisations $\mathrm{s}^{544}$ for the period (a) 2000-2016 and (b) 2000-2050 under the $2^{\circ} \mathrm{C}$ climate policy545 framework including both direct and indirect emissions for all technologies. $\quad 5$ when studying European emissions. However, the differences ${ }^{548}$ in means between costs optimisation and environmental opti- ${ }^{549}$ misation were significant $(\mathrm{p}<0.05)$ in all the NEEDS scenario ${ }^{550}$ cases. This supports the claim that environmental optimisation ${ }^{551}$ can achieve a lower emissions rate than costs optimisation in ${ }^{552}$ the long run, despite the use of the ETS framework. The emis- ${ }^{55}$ sions optimisations gave on average (for all NEEDS scenarios) ${ }^{554}$ $30.0 \%$ lower emissions levels than costs optimisation under the ${ }^{555}$ $2{ }^{\circ} \mathrm{C}$ climate policy framework.

Raw emissions can also be converted into accumulated $\mathrm{CO}_{2}{ }^{557}$ in the atmosphere, expressed in ppm. The accumulated emis- ${ }^{558}$ sions are presented in Figure 3. At the European level, elec- ${ }^{55}$ tricity production for the 24 countries contributed to raising the ${ }^{560}$ $\mathrm{CO}_{2}$ concentration by $6.27 \mathrm{ppm}$ from 2000 to 2050 , or 0.13 ppm/ye In contrast, the average increase in GHG occurs at a pace of ${ }^{562}$ $2.10 \mathrm{ppm} /$ year world-wide and the concentration reached $405 \mathrm{ppm}$ in November 2017 [41]. Note that, as mentioned earlier, biomass reabsorption was disregarded in the life cycle impact assess- ${ }^{565}$ ment and could thus be deducted from the resulting emissions. ${ }^{56}$ Furthermore, a gap arises when power production is managed ${ }^{567}$ under economic merit order driven by the carbon tax compared ${ }^{568}$ with an environmental merit order. This gap could suggest that ${ }^{569}$ the economic incentive to decrease carbon-intensive produc- ${ }^{57}$ tion systems reaches a limit and that greater reductions could ${ }^{571}$ be achieved by considering the environmental impact of these ${ }^{572}$ power production systems.

\subsection{Impacts on infrastructure}

Inclusion of an environmental objective in handling elec- 576 tricity production to satisfy demand obviously affects the infrastructure of the power system. Therefore, in the EUTGRID model, the grid development infrastructure is re-evaluated on $\mathrm{a}_{580}$ five-year basis. The infrastructure should be able to integrate ${ }_{581}$ as much VRES as possible and thus avoid curtailments. The EUTGRID model looks at the development of both HVAC and HVDC lines for satisfying the demand. The development of these networks has different costs. The difference between a costs optimisation system and an environmental optimisation system is depicted in Figure 5.

From this perspective, it is possible to compare the optimisation objectives by looking at the total required capacity of HVAC and HVDC lines, the deployed length of those lines, the total installed capacity and the corresponding investments for grid reinforcement between 2010 and 2050.

The main difference in technology developments for transmission grids between the costs and environmental optimisations is that HVAC is preferred in environmental optimisation, while HVDC is preferred in costs optimisation. Thus in the present case environmental optimisation required the installation of $275 \mathrm{GW}(\sigma=11)$ of capacity, representing $57100 \mathrm{~km}$ $(\sigma=3200)$ of HVAC lines, while costs optimisation required $270 \mathrm{GW}$ of capacity for $54600 \mathrm{~km}$ of HVDC lines. On the other hand, the added HVDC lines resulted in $115 \mathrm{GW}$ of new installed capacity $(42600 \mathrm{~km})$ in the cost optimisation approach, while the environmental optimisation had lower capacity at 111 GW $(\sigma=7.50)$ and $42600 \mathrm{~km}(\sigma=1670)$.

Installation of these new lines involved different level of investments. Overall, the cost optimisation resulted in an investment plan of 315 billion US\$ for the period 2010-2050. The environmental optimisation had a mean investment plan of 321 billion US $\$(\sigma=8.30)$ for the same period. These costs reflect only the investments required by the transmission network to reinforce its capacity for transporting electricity. Nevertheless, the carbon intensity of the investments from the environmental optimisation were found to be much lower than in the case of costs optimisation, as summarised in Table 1.

As the investments increased, the climate change-related environmental impact decreased overall. Therefore, the costs optimisation approach had the highest carbon intensity on the investments needed to reach the $2^{\circ} \mathrm{C}$ climate scenario $\left(130 \mathrm{kgCO}_{2 \mathrm{eq}} / \$_{\text {inv }}\right)$, although it followed the least costly trajectory and therefore incontestably the lowest electricity system cost. In contrast, the greenest pathway was the scenario VO-Renew, with a carbon intensity of $91 \mathrm{kgCO}_{2 \mathrm{eq}} / \$_{i n v}$ although all the environmental emissions optimisation scenarios had on average a carbon intensity of $96 \mathrm{kgCO}_{2 \mathrm{eq}} / \$_{i n v}(\sigma=3.6)$. To compare the different alternatives and define which one is to be preferred, the stochastic multiobjective acceptability analysis (SMAA) [30, 42] was applied. The SMAA approach allows comparing and ranking the alternatives between each other's, giving to decision-makers information about the most interesting alternative. The three criteria - investments, emissions, system cost - were used to rank the alternatives. First, we analysed each alternative individually. Then, emission optimisations were averaged and the related standard deviation calculated to be used in a Gaussian distribution. Results indicate that the EUTGRID - CC VO-440ppm was the favoured alternative (rank acceptability $a=0.64)$ before the cost optimisation $(a=0.36)$. In case the emission optimisations were put together, there was no clear winning alternative, meaning that any of them would be appro- 
This is the final manuscript author version. (C2018. This manuscript version is made available under the CC-BY-NC-ND 4.0 license http://creativecommons.org/licenses/by-nc-nd/4.0/ doi:10.1016/j.energy.2018.08.093

Env. Optimisation - Climate Policy Cost Optimisation - Climate Policy

$\Delta$ Cost Optimisation - BAU Policy
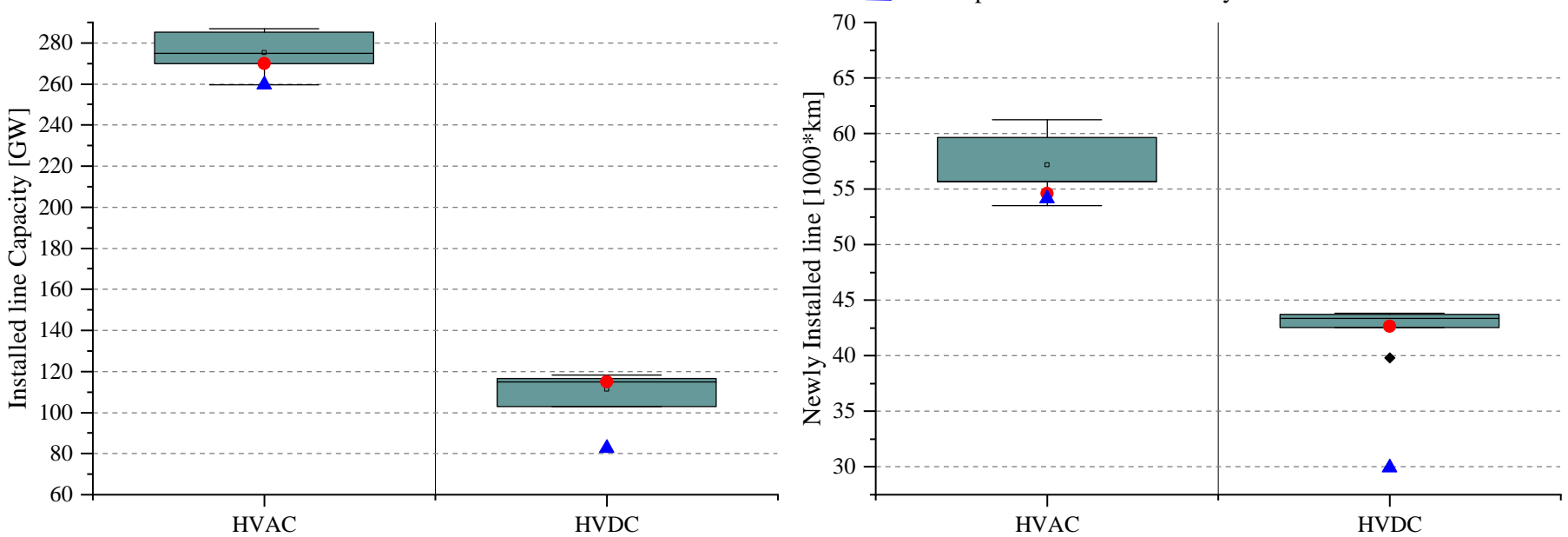

(a)
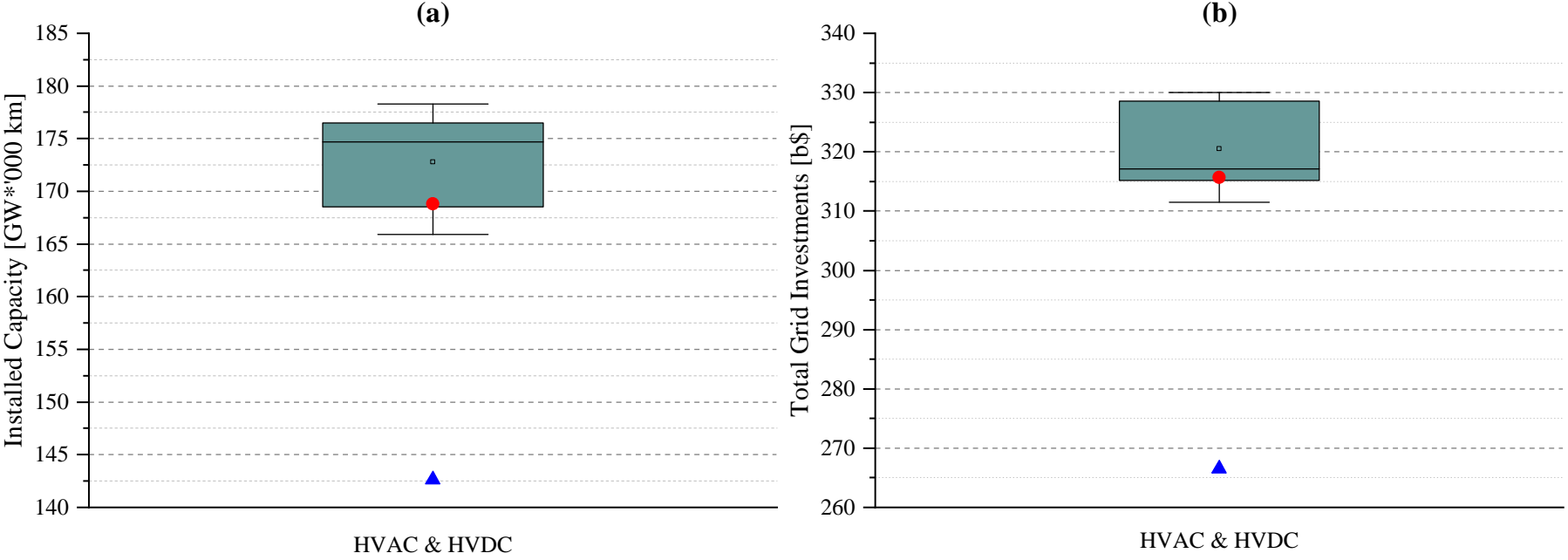

(c)

(d)

Figure 5: Improvements required in transmission line infrastructure in environmental optimisation and costs optimisation of the electricity system at the European level (EU24) for the period 2010-2050. The infrastructure changes comprised (a) new line capacity and (b) relationship to the length of line installed, (c) summarised for the entire power system and (d) the total investments needed for the power system to support the use of more variable renewable energy sources (VRES).

Table 1: Carbon intensity of investments made in the pan-European electricity transmission network for the period 2010-2050 under costs and environmental (emissions) optimisation.

\begin{tabular}{|c|c|c|c|c|c|}
\hline Optimisation & Scenario & $\begin{array}{l}\text { Grid infrastructure } \\
\text { investments } \\
{\left[\mathrm{b} \$_{i n v}\right]}\end{array}$ & $\begin{array}{l}\text { System cost } \\
{\left[\mathrm{b} \$_{i n v}\right]}\end{array}$ & $\begin{array}{l}\text { Emissions } \\
{\left[\mathrm{MtCO}_{2 \mathrm{eq}}\right]}\end{array}$ & $\begin{array}{l}\text { Carbon intensity } \\
{\left[\mathrm{kgCO}_{2 \mathrm{eq}} / \$_{i n v}\right]}\end{array}$ \\
\hline Cost & - & 316 & 7483 & 41032 & 130 \\
\hline \multirow[t]{5}{*}{ Emissions } & EUTGRID - CC - P-BAU & 329 & 9821 & 30899 & 94 \\
\hline & EUTGRID - CC - P-440ppm & 315 & 9460 & 32094 & 102 \\
\hline & EUTGRID - CC - RO-440ppm & 317 & 9377 & 31150 & 98 \\
\hline & EUTGRID - CC - VO-440ppm & 312 & 9408 & 30012 & 96 \\
\hline & EUTGRID - CC - VO-Renew & 330 & 9420 & 30102 & 91 \\
\hline
\end{tabular}

J-N. Louis, S. Allard, V. Debusschere, S. Mima, T. Tran-Quoc, N. Hadjsaid, Environmental impact indicators for the electricity mix and network development planning towards 2050 - A POLES and EUTGRID model, Energy, 163, 2018, p.618-628, doi:10.1016/j.energy.2018.08.093 
This is the final manuscript author version. (C2018. This manuscript version is made available under the CC-BY-NC-ND 4.0 license http: //creativecommons.org/licenses/by-nc-nd/4.0/ doi:10.1016/j.energy.2018.08.093

priate. Nevertheless, giving preferences to the environmental 635 weight criteria over the cost criteria put the emission optimisa-6зе tion alternative a rank acceptability of 0.93 , meaning that it is637 clearly the best alternative to enforce. However, giving prefer-63 ences to any cost related criteria placed the cost optimisation as the best alternative with a rank acceptability of 0.97 . The 640 SMAA analysis data are available in SI [31].

\subsection{Criteria based on other emissions}

The model was primarily designed to optimise climate changet related emissions. However, any other kind of environmental ${ }^{645}$ criterion can be set as an objective function. As mentioned ear- ${ }^{646}$ lier, under high penetration of VRES it is foreseeable that $\mathrm{nu}^{-647}$ clear will, to some extent and including technical constraints, ${ }^{648}$ contribute to balancing power $[33,3]$.

For this reason, we examined the possibility of using nu-650 clear power plant flexibility to reduce ionising radiation at the ${ }^{651}$ network level, as nuclear is the main contributor to this environ- ${ }^{-52}$ mental indicator. Extreme scenarios such as nuclear disasters ${ }^{653}$ were not considered when including the nuclear power plant ${ }^{654}$ flexibility, as they represent another set of scenarios. Although ${ }^{655}$ a small decrease in nuclear usage was identified compared with ${ }^{656}$ the climate change indicator optimisation, it was not statisti- ${ }^{657}$ cally significant $(\mathrm{p}>0.05)$. This implies that including ionising ${ }^{658}$ radiation in the optimisation equation does not influence the ${ }^{659}$ overall emissions as such and that using nuclear power flexi-660 bility for environmental purposes does not make any significant ${ }^{66}$ difference.

Other indicators were not investigated, as they did not fall ${ }^{663}$ within the scope of decarbonisation.

\section{Conclusions}

This study investigated the impact of using purely environ- ${ }^{6}$ mental criteria as the merit order system under carbon tax in- ${ }^{669}$ centives. A combined POLES and EUTGRID model was used ${ }^{670}$ for this purpose. To include environmental considerations in the decision-making process, a combined module using current and $\mathrm{d}^{672}$ prospective LCA methodologies was added to the EUTGRID ${ }^{673}$ model.

The share of RES in the European electricity mix increased ${ }^{675}$ by $2.65 \%$ under environmental optimisation compared with $\operatorname{costs}^{676}$ optimisation, which is more conservative. There was also a dif- ${ }^{677}$ ference in strategies for power production management. $\mathrm{Cli}^{6}{ }^{678}$ mate change criteria favoured the use of offshore wind produc ${ }^{679}$ tion and decreased the use of coal-based generation at the Euro ${ }^{-680}$ pean level, under the same climate policy constraints. The en ${ }^{681}$ ergy mix varied only slightly at the European level, but with in- ${ }^{682}$ tegration of VRES it varied significantly from country to coun- ${ }^{-63}$ try, even to the extent of changing market strategies. In some ${ }^{684}$ cases, some countries (e.g. Austria) changed from importing to exporting power and some (e.g. Norway) did the opposite. 685

Shifting from an economic to an environmental merit order, but still keeping economic growth consideration from POLES, ${ }^{686}$ decreased overall emissions by $9.00 \%$. As time passed and the ${ }^{687}$ system became increasingly decarbonised, the $\mathrm{CO}_{2 \mathrm{eq}}$ emissions ${ }^{688}$ decreased and tended to converge. However, emissions based on environmental criteria decreased faster and therefore the cumulative emissions concentration in the atmosphere was lower than in the optimisation based on economic objectives. In a way, managing power production based only on an economic merit order will inevitably result in more cumulative $\mathrm{CO}_{2 \mathrm{eq}}$ emissions in the long run than a system based on an environmental merit order. In that case, however, the use of various environmental impacts from LCA studies did not show a significant difference. Moreover, the change of power management is accompanied by a change in infrastructure planning.

The power infrastructure has to evolve to integrate more VRES in the network. With environmental optimisation, the investments in HVAC reinforcements and new lines were slightly higher in power but much higher in distance, implying more low-power HVAC lines. The changes in infrastructure also involved higher costs in the environmental optimisation case, by 6.00 billion US $\$$ or $+1.50 \%$ compared with costs optimisation.

Climate policy drives the change in power production through economic incentives. Current policy can reach the decarbonisation target set by the EU using a least-cost trajectory. Our research suggests that considering a purely environmental, instead of an economic, merit order would allow decarbonisation to be achieved slightly faster, resulting in lower cumulative GHG emissions to the atmosphere. The gain on the environmental side comes with higher investments in the power system but is counterbalanced by the greater amount of non-emitted GHG. This suggests that including an environmental indicator in the decision-making process on the power system would result in higher investments but would bring more cumulative environmental gains.

The integration of characterised LCA emissions factors involved uncertainty at all levels, and the results should be regarded as a 'best guess'. Work is underway world-wide to produce the best environmental impact estimates for future technologies. As the EUTGRID model is dependent on POLES to set the energy mix per country, in this study it was not possible to influence the investments in the energy production system, which shaped the energy mix for each country up to 2050.

However, environmental impact could be integrated in the upper layer of the EUTGRID model, directly in POLES. It would act as complementary information to the carbon tax already in place and influence the decision-making process. Furthermore, to balance the system, other environmental indicators should be investigated, such as particulate matter formation, which has direct impacts on human health. Our next goal is to find the sweet spot between infrastructure investments costs, environmental emissions and actual system costs. We have already started work on this, in the form of a multi-objective optimisation.

\section{Acknowledgments}

This research was made possible by funding provided by the Academy of Finland for the SEN2050 project (Decision 287748) and strategic funding for research at the University of 
This is the final manuscript author version. (92018. This manuscript version is made available under the CC-BY-NC-ND 4.0 license http: //creativecommons.org/licenses/by-nc-nd/4.0/ doi:10.1016/j.energy.2018.08.093

Oulu, and a grant from the ARC-4 Energies Région Auvergne 755 Rhône-Alpes, France.

\section{References}

\section{References}

[1] Allard, S., Mima, S., Debusschere, V., Quoc, T.T., Criqui, P., HadjSaïd, ${ }_{764}^{763}$ N., 2018. Large scale integration of variable renewable energies in the European power system: a model POLES-EUTGRID based approach. ${ }_{765}$ 2018 International Energy Workshop

[2] Arvesen, A., Luderer, G., Pehl, M., Bodirsky, B.L., Hertwich, E.G., $2018^{767}$ Deriving life cycle assessment coefficients for application in integrated ${ }_{769}^{768}$ assessment modelling. Environmental Modelling \& Software 99, 111- ${ }_{770}$ 125. doi:doi:10.1016/j.envsoft.2017.09.010.

[3] Cany, C., Mansilla, C., Mathonnière, G., da Costa, P., 2018. $\mathrm{Nu}^{771}$ clear contribution to the penetration of variable renewable energy ${ }_{773}^{772}$ sources in a French decarbonised power mix. Energy 150, 544-555. ${ }_{774}^{773}$ doi:doi:10.1016/j.energy.2018.02.122.

[4] Capros, P., Paroussos, L., Fragkos, P., Tsani, S., Boitier, B., Wagner, F., ${ }^{775}$ Busch, S., Resch, G., Blesl, M., Bollen, J., 2014. Description of models ${ }_{777}^{776}$ and scenarios used to assess european decarbonisation pathways. Energy ${ }_{778}^{777}$ Strategy Reviews 2, 220-230. doi:doi:10.1016/j.esr.2013.12.008.

[5] Collins, S., Deane, J., Gallachóir, B.Ó., 2017. Adding value ${ }^{779}$ to EU energy policy analysis using a multi-model approach with ${ }_{78}^{780}$ an EU-28 electricity dispatch model. Energy 130, 433-447. ${ }_{788}^{781}$ doi:doi:10.1016/j.energy.2017.05.010.

[6] Corona, B., Ruiz, D., Miguel, G.S., 2016. Life cycle assessment of $a^{783}$ HYSOL concentrated solar power plant: Analyzing the effect of geo- ${ }_{785}$ graphic location. Energies 9, 413. doi:doi:10.3390/en9060413.

[7] Crippa, M., Janssens-Maenhout, G., Dentener, F., Guizzardi, D., Sinde- ${ }_{787}^{786}$ larova, K., Muntean, M., Dingenen, R.V., Granier, C., 2016. Forty years ${ }^{787}$ of improvements in european air quality: regional policy-industry interac- ${ }_{788}^{789}$ tions with global impacts. Atmospheric Chemistry and Physics 16, 3825- ${ }_{790}$ 3841. doi:doi:10.5194/acp-16-3825-2016.

[8] Criqui, P., Mima, S., 2006. The POLES model - State of ${ }^{791}$ the Art. Technical Report January. Laboratoire d'Economie ${ }^{792}$ de la Production et de l'Intégration Internationale. URL: ${ }_{794}^{793}$ https : //web.archive.org/web/20061230191956/http: // webu2 . upmf-grenoble.fr/iepe/textes/POLES12p_Jan06.pdf. ${ }^{795}$

[9] Després, J., 2015. Modelling the long-term deployment of electric- ${ }^{796}$ ity storage in the global energy system. Ph.D. thesis. G2ELab ${ }_{-}^{797}$ Laboratoire de Génie Electrique de Grenoble. URL: https://tel ${ }_{799}^{798}$ archives-ouvertes.fr/tel-01231455/.

[10] Després, J., HadjSaïd, N., Criqui, P., Noirot, I., 2015. Modelling the ${ }^{800}$ impacts of variable renewable sources on the power sector: Reconsid- ${ }^{801}$ ering the typology of energy modelling tools. Energy 80, 486-495. ${ }^{802}$ doi:doi:10.1016/j.energy.2014.12.005.

[11] Després, J., Mima, S., Kitous, A., Criqui, P., HadjSaïd, N., Noirot, I., ${ }^{804}$ 2017. Storage as a flexibility option in power systems with high shares of variable renewable energy sources: a POLES-based analysis. Energy ${ }_{807}^{806}$ Economics 64, 638-650. doi:doi:10.1016/j.eneco.2016.03.006.

[12] Durach, C.F., Wiengarten, F., 2017. Environmental management: The ${ }_{808}^{808}$ impact of national and organisational long-term orientation on plants' en- ${ }_{810}^{809}$ vironmental practices and performance efficacy. Journal of Cleaner Pro- ${ }_{81}^{810}$ duction doi:doi:10.1016/j.jclepro.2017.08.183.

[13] E3Mlab, 2016. PRIMES model, version 6. Technical Report. National ${ }_{813}^{812}$ Technical University of Athens. URL: http://www.e3mlab.ntua ${ }_{814}^{813}$ gr/.

[14] EDDEN, 2017. POLES-EDDEN - global energy model. URL: ${ }_{816}^{815}$ https://gael.univ-grenoble-alpes.fr/presentation/ $\quad 816$ axe-energie/modele-poles.

[15] Enerdata, 2017. POLES-ENERDATA - global energy model. URL: ${ }_{819}^{818}$ https ://www . enerdata.net/solutions/poles-model.html.

[16] European Commission, 2011. Energy Roadmap 2050. Technical Report ${ }_{821}^{820}$ SEC(2011) 1565 final. European Commission. Brussels.

[17] European Commission, 2012. Biomass issues in the EU ETS.

[18] European Council, 2009. Brussels European Council 29/30 octo- ${ }^{823}$ ber 2009 presidency conclusions, ST 152652009 REV 1. URL: ${ }_{825}^{824}$ https://www.consilium.europa.eu/uedocs/cms_data/docs / pressdata/en/ec/110889.pdf

[19] García-Gusano, D., Iribarren, D., Martín-Gamboa, M., Dufour, J., Espegren, K., Lind, A., 2016a. Integration of life-cycle indicators into energy optimisation models: the case study of power generation in Norway. Journal of Cleaner Production 112, 2693-2696. doi:doi:10.1016/j.jclepro.2015.10.075.

[20] García-Gusano, D., Martín-Gamboa, M., Iribarren, D., Dufour, J., 2016b. Prospective analysis of life-cycle indicators through endogenous integration into a national power generation model. Resources 5, 39 . doi:doi:10.3390/resources5040039.

[21] Goedkoop, M., Heijungs, R., Huijbregts, M., De Schryver, A., Struijs, J., van Zelm, R., 2013. ReCiPe 2008: A life cycle impact assessment method which comprises harmonised category indicators at the midpoint and the endpoint level. Technical Report. PRé Sustainability.

[22] Hawkins, E., Ortega, P., Suckling, E., Schurer, A., Hegerl, G., Jones, P., Joshi, M., Osborn, T.J., Masson-Delmotte, V., Mignot, J., Thorne, P., van Oldenborgh, G.J., 2017. Estimating changes in global temperature since the pre-industrial period. Bulletin of the American Meteorological Society doi:doi:10.1175/bams-d-16-0007.1.

[23] IEA, 2012. Energy Policies of IEA countries - The Slovak Republic 2012 Review. International Energy Agency. URL: https://www.iea.org/ publications/countryreviews/.

[24] IEA, 2013. Energy Policies of IEA countries - Finland 2013 Review. International Energy Agency. URL: https://www.iea.org/ publications/countryreviews/.

[25] Keramidas, K., Kitous, A., 2017. Global Energy and Climate Outlook 2017: Greenhouse gas emissions and energy balances - Supplementary material to "Global Energy and Climate Outlook 2017: How climate policies improve air quality". Technical Report EUR 28725 EN. Joint Research Centre (Seville site). doi:doi:10.2760/034229. publications Office of the European Union, Luxembourg.

[26] Keramidas, K., Kitous, A.G., Després, J., Schmitz, A., 2017. POLES-JRC model documentation. EUR 28728 EN, Joint Research Centre (European Commission), Publications Office of the European Union, Luxembourg. doi:doi:10.2760/225347.

[27] Kitous, A., Criqui, P., Bellevrat, E., Chateau, B., 2010. Transformation patterns of the worldwide energy system - scenarios for the century with the POLES model. The Energy Journal 31. doi:doi:10.5547/issn01956574-ej-vol31-nosi-3.

[28] Kitous, A., Keramidas, K., Vandyck, T., Saveyn, B., Van Dingenen, R., Spadaro, J., Holland, M., 2017. Global Energy and Climate Outlook 2017: How climate policies improve air quality - Global energy trends and ancillary benefits of the Paris Agreement. Technical Report EUR 28798 EN. Joint Research Centre (Seville site). doi:doi:10.2760/474356. publications Office of the European Union, Luxembourg.

[29] Kotrla, M., Mandalová, K., Prčík, M., 2017. Regional disparities in slovakia and the czech republic in the context of sustainable growing of energy plants. European Journal of Sustainable Development 6, 165179. URL: https://ecsdev .org/ojs/index.php/ejsd/article/ view/476, doi:doi:10.14207/ejsd.2017.v6n2p165.

[30] Lahdelma, R., Hokkanen, J., Salminen, P., 1998. SMAA - stochastic multiobjective acceptability analysis. European Journal of Operational Research 106, 137-143. doi:doi:10.1016/s0377-2217(97)00163-x.

[31] Louis, J.N., 2018. Data for: Environmental impact indicators for the electricity mix and network development planning towards 2050 - a POLES and EUTGRID model. Mendeley Data, v1. doi:doi:10.17632/bch6yb6j63.1.

[32] Loulou, R., Goldstein, G., Kanudia, A., Lehtila, A., Remme, U., 2016. Documentation for the TIMES model - Part I TIMES concepts and theory. techreport. Energy Technology Systems Analysis Programme. URL: http: //iea-etsap.org/index.php/documentation.

[33] Martinez-Anido, C.B., Botor, B., Florita, A.R., Draxl, C., Lu, S., Hamann, H.F., Hodge, B.M., 2016. The value of day-ahead solar power forecasting improvement. Solar Energy 129, 192-203. doi:doi:10.1016/j.solener.2016.01.049.

[34] McDowall, W., Rodriguez, B.S., Usubiaga, A., Fernández, J.A., 2018. Is the optimal decarbonization pathway influenced by indirect emissions? incorporating indirect life-cycle carbon dioxide emissions into a european TIMES model. Journal of Cleaner Production 170, 260-268. doi:doi:10.1016/j.jclepro.2017.09.132. 
This is the final manuscript author version. (C2018. This manuscript version is made available under the CC-BY-NC-ND 4.0 license http: //creativecommons .org/licenses/by-nc-nd/4 .0/ doi:10.1016/j.energy.2018.08.093

[35] Pang, X., Mörtberg, U., Brown, N., 2014. Energy models from a strategic environmental assessment perspective in an EU context-what is missing concerning renewables? Renewable and Sustainable Energy Reviews 33, 353-362. doi:doi:10.1016/j.rser.2014.02.005.

[36] Pehl, M., Arvesen, A., Humpenöder, F., Popp, A., Hertwich, E.G., Luderer, G., 2017. Understanding future emissions from low-carbon power systems by integration of life-cycle assessment and integrated energy modelling. Nature Energy 2, 939-945. doi:doi:10.1038/s41560-0170032-9.

[37] Portugal-Pereira, J., Köberle, A.C., Soria, R., Lucena, A.F., Szklo, A., Schaeffer, R., 2016. Overlooked impacts of electricity expansion optimisation modelling: The life cycle side of the story. Energy 115, 1424-1435. doi:doi:10.1016/j.energy.2016.03.062.

[38] Ricci, A., Frischknecht, R., Hedemann, J., Bauer, C., Mayer-Spohn, O., Maack, M., Lavagno, E., Pehnt, M., Krewitt, W., Hassan, A.A., Lombardelli, S., Gärtner, S., Boulch, D.L., Sörensen, H.C., 2009. New Energy Externalities Developments for Sustainability (NEEDS) - Publishable Final Activity Report M1-M54. Technical Report. Institute of Studies for the Integration of Systems. URL: http: //www . needs - project.org/.

[39] San Miguel, G., 2017. Personal communication.

[40] Soimakallio, S., Kiviluoma, J., Saikku, L., 2011. The complexity and challenges of determining GHG (greenhouse gas) emissions from grid electricity consumption and conservation in LCA (life cycle assessment) - a methodological review. Energy 36, 6705-6713. doi:doi:10.1016/j.energy.2011.10.028.

[41] Tans, P., Keeling, R., 2017. Trends in atmospheric carbon dioxide. National Oceanic and Atmospheric Administration, Earth System Research Laboratory, Global Monitoring Division. URL: www.esrl.noaa.gov/ gmd/ccgg/trends/.

[42] Tervonen, T., 2012. JSMAA: open source software for SMAA computations. International Journal of Systems Science 45, 69-81. doi:doi:10.1080/00207721.2012.659706.

[43] United Nations, 1998. Kyoto protocol to the united nations framework convention on climate change - Doc FCCC/CP/1997/7/Add.1, 37 I.L.M. 22 (1998). URL: http://unfccc.int/kyoto_protocol/items/ 2830.php.

[44] United Nations, 2015. The Paris Agreement. URL: http://unfccc. int/paris_agreement/items/9485.php.

[45] Urbančič, N., Ambel, C.C., 2015. Reasons to change the zero-rated criteria for biomass in the EU ETS. Technical Report. BirdLife, European Environmental Bureau, and Transport \& Environment. URL: https://www.transportenvironment.org/publications / reasons-change-zero-rated-criteria-biomass-eu-ets.

[46] Wernet, G., Bauer, C., Steubing, B., Reinhard, J., Moreno-Ruiz, E., Weidema, B., 2016. The ecoinvent database version 3 (part I): overview and methodology. The International Journal of Life Cycle Assessment 21, 1218-1230. doi:doi:10.1007/s11367-016-1087-8.

[47] Wu, F., Zheng, F., Wen, F., 2006. Transmission investment and expansion planning in a restructured electricity market. Energy 31, 954-966. doi:doi:10.1016/j.energy.2005.03.001.
Table A.2: Abbreviations and related units in the ReCiPe environmental impact characterisation method.

\begin{tabular}{|c|c|c|}
\hline Indicator & Abb. & Unit $\left[/ \mathrm{kWh}_{\text {pro }}\right]$ \\
\hline Climate change & $\mathrm{CC}$ & $\mathrm{kgCO}_{2 \mathrm{eq}}$ \\
\hline Ozone depletion & OD & $\mathrm{kgCFC}-11_{\mathrm{eq}}$ \\
\hline Terrestrial acidification & TA & $\mathrm{kgSO}_{2 \mathrm{eq}}$ \\
\hline Freshwater eutrophication & $\mathrm{FE}$ & $\mathrm{kgP}_{\mathrm{eq}}$ \\
\hline Marine eutrophication & $\mathrm{ME}$ & $\mathrm{kgN}_{\mathrm{eq}}$ \\
\hline Human toxicity & $\mathrm{HT}$ & $\mathrm{kg} 1,4-\mathrm{DB}_{\mathrm{eq}}$ \\
\hline Photochemical oxidant formation & POF & kgNMVOC \\
\hline Particulate matter formation & $\mathrm{PMF}$ & $\mathrm{kgPM}_{10}$ \\
\hline Terrestrial ecotoxicity & TEco & $\mathrm{kg} 1,4-\mathrm{DB}_{\mathrm{eq}}$ \\
\hline Freshwater ecotoxicity & FEco & $\mathrm{kg} 1,4-\mathrm{DB}_{\mathrm{eq}}$ \\
\hline Marine ecotoxicity & MEco & $\mathrm{kg} 1,4-\mathrm{DB}_{\mathrm{eq}}$ \\
\hline Ionising radiation & IR & $\mathrm{kBqU} 235_{\mathrm{eq}}$ \\
\hline Agricultural land occupation & $\mathrm{ALO}$ & $\mathrm{m}^{2} \mathrm{a}$ \\
\hline Urban land occupation & ULO & $\mathrm{m}^{2} \mathrm{a}$ \\
\hline Natural land transformation & NLT & $\mathrm{m}^{2}$ \\
\hline Water depletion & WD & $\mathrm{m}^{3}$ \\
\hline Metal depletion & MD & $\mathrm{kgkgFe}_{\mathrm{eq}}$ \\
\hline Fossil depletion & FD & $\mathrm{kgOil}_{\mathrm{eq}}$ \\
\hline
\end{tabular}

\section{Appendix A. Indicators}

J-N. Louis, S. Allard, V. Debusschere, S. Mima, T. Tran-Quoc, N. Hadjsaid, Environmental impact indicators for the electricity mix and network development planning towards 2050 - A POLES and EUTGRID model, Energy, 163, 2018, p.618-628, doi:10.1016/j.energy.2018.08.093 
This is the final manuscript author version. (C2018. This manuscript version is made available under the CC-BY-NC-ND 4.0 license http: //creativecommons .org/licenses/by-nc-nd/4.0/ doi:10.1016/j.energy.2018.08.093

Table A.3: The 41 current and prospective technologies considered in the EUTGRID and POLES model of the electricity production system.

\begin{tabular}{|c|c|}
\hline Abbreviation & Name \\
\hline NUC & Conventional nuclear design \\
\hline NND & New nuclear design (4th generation) \\
\hline PFC & pressurised coal supercritical \\
\hline PSS & pressurised coal supercritical with CCS \\
\hline ICG & Integrated coal gasification with combined cycle (CC) \\
\hline ICS & Integrated coal gasification with Combined Cycle and CCS \\
\hline LCT & Lignite \\
\hline $\mathrm{CCT}$ & Coal Conventional Thermal \\
\hline GCT & Gas Conventional Thermal \\
\hline GGT & Gas turbine \\
\hline GGC & Gas Combined Cycle \\
\hline GGS & Gas Combined Cycle with CCS \\
\hline OCT & Oil Conventional thermal \\
\hline OGC & Oil Combined Cycle \\
\hline HRR & Hydraulic run-of-river \\
\hline HLK & Hydraulic with reservoir (lake) \\
\hline HPS & Pumped hydro \\
\hline SHY & Small hydro $(<10 \mathrm{MW})$ \\
\hline OCE & Tidal and wave \\
\hline GEO & Geothermal \\
\hline BTE & Biomass Conventional Thermal \\
\hline BGTE & Biomass and Gasification \\
\hline BGAE & Biogas \\
\hline BCS & Biomass Conventional Thermal with CCS \\
\hline BTC & Biomass with combined heat and power (CHP) \\
\hline BGTC & Biomass and Gasification with CHP \\
\hline BGAC & Biogas with CHP \\
\hline $\mathrm{BWC}$ & Biodegradable waste with CHP \\
\hline WN1 & Wind onshore with different wind quality resource (1) \\
\hline WN2 & Wind onshore with different wind quality resource (2) \\
\hline WN3 & Wind onshore with different wind quality resource (3) \\
\hline WO1 & Wind offshore with different wind quality resource (1) \\
\hline WO2 & Wind offshore with different wind quality resource (2) \\
\hline WO3 & Wind offshore with different wind quality resource (3) \\
\hline $\mathrm{CPV}$ & PV power plant (centralised) \\
\hline DPV & Decentralised PV \\
\hline SPP & Solar thermal power plant \\
\hline SPPS & Solar thermal power plant with thermal storage \\
\hline $\mathrm{CHP}$ & Coal Conventional Thermal \\
\hline $\mathrm{HFC}$ & Hydrogen fuel cell \\
\hline GFC & Gas fuel cells \\
\hline
\end{tabular}

J-N. Louis, S. Allard, V. Debusschere, S. Mima, T. Tran-Quoc, N. Hadjsaid, Environmental impact indicators for the electricity mix and network development planning towards 2050 - A POLES and EUTGRID model, Energy, 163, 2018, p.618-628, doi:10.1016/j.energy.2018.08.093 